\title{
INTRAMEDULLARY NAILING OF BOTH BONE FOREARM FRACTURES IN CHILDREN BY RUSH NAILS AND TITANIUM ELASTIC NAILS
}

\author{
Dr Rajeev Dwivedi ${ }^{1,}$ Dr Ruban Joshi ${ }^{2}$, Dr Subin Byanjankar ${ }^{2}$, Dr Sagar Panthi ${ }^{2}$,Dr Rahul Shreshtha ${ }^{2}$, Dr Som Ale ${ }^{2}$
}

\begin{abstract}
INTRODUCTION:

Forearm fractures are common upper limb injuries among children and usually treated nonoperatively. Failure of nonoperative treatment, open injuries and multiple fractures are the indications for surgery in paediatric both bone forearm fractures. Intramedullary (IM) nailing is considered as minimally invasive procedure with excellent to fair outcomes but it is not free of complications. We reviewed the results and compared the outcomes of IM fixation by Rush nails with titanium elastic nails (TENs), to understand the risks and complications associated with this procedures.
\end{abstract}

\section{MATERIAL AND METHODS:}

We performed a retrospective review of all paediatric patients treated for diaphyseal forearm fractures from January 2011 to December 2015. Complications were classified according to modified Clavien-Dindo complication classification system. Outcomes were graded depending upon complication grade along with range of motion of forearm.

\section{RESULTS:}

There was no statistically significant difference for mean time to fracture union between the Rush nailing (10.56 weeks ) group and TENs nailing group $(9.85$ weeks $)(\mathrm{P}=0.43)$. There was no statistically significant difference in outcomes between Rush nailing and TENs nailing group $\mathrm{p}=0.65$. In Rush nailing group outcomes were excellent in $16(64 \%)$,good in $7(28 \%)$, fair in $2(8 \%)$ patients and no poor outcome were noted .In TENs nailing group outcomes were excellent in $11(55 \%)$, good in $6(30 \%)$, fair in $3(15 \%)$ patients and no poor outcomes were noted.

\section{CONCLUSION:}

Fixation of pediatric forearm fractures by intramedullary Rush nails and titanium elastic nails (TENs) are minimally invasive procedures and results are excellent to fair with acceptable complication rates. Since Rush nails are easily available and affordable in developing countries like ours we can prefer Rush nails for intramedullary fixation of paediatric forearm fracture when indicated.

KEY WORDS: Complication, forearm fractures, intramedullary nailing, outcome, paediatrics, Rush nails, titanium elastic nails,.

1. Asst. Professor, Department of Orthopaedics, Lumbini Medical College and Teaching Hospital,Tansen ,Palpa, Nepal

2. Department of Orthopaedics, Lumbini Medical College and Teaching Hospital, Tansen,Palpa, Nepal

\author{
For Correspondence: \\ Dr Rajeev Dwivedi, \\ Asst. Professor \\ Department of Orthopaedics, \\ Lumbini Medical College and Teaching Hospital, Palpa, Nepal \\ E-mail:rd172002@gmail.com
}




\section{INTRODUCTION:}

Diaphyseal forearm fractures are common upper limb injuries among children .Nonoperative treatment in the form of close reduction and cast application is the standard method for treating most of these fractures, as most of the children with displaced forearm fractures achieve satisfactory results with this treatment. ${ }^{1}$ Operative treatment of pediatric forearm fractures is indicated for patients in whom satisfactory alignment cannot be achieved by close reduction and cast application, in multiple bone fractures and in compound fractures .

Results of nonoperative treatment of paediatric diaphyseal forearm fractures are favourable in the majority of cases, despite of that surgical treatment for such injuries are increasing nowadays. A study showed an increase in the rate of surgical treatment of paediatric forearm fractures in the form of intramedullary (IM) nailing from $1.8 \%$ to $22 \%$ over a 10 year period. ${ }^{2}$ Increasing trend towards operative treatment of paediatric forearm fractures may be due to technologic advances and its accessibility, awareness of parents, and liability concerns of surgeons and may be due to medical economics.

Intramedullary (IM) nailing of pediatric forearm fractures is considered as minimally invasive procedure when compared with open reduction and plate fixation which is the standard treatment for similar fractures in adult. IM nailing of forearm fractures can be done by closed method but in certain circumstances minimal opening is made to open the fracture site when reduction is difficult due to soft tissue interposition or due to difficulty in engaging the nail. Several studies have shown excellent to good results of IM nailing of paediatric forearm fractures, leading to increase in practice of IM fixation of such injuries ${ }^{3,4}$ But there are several minor and major complications of IM fixation, including delayed union, nonunion, need to frequently expose the fracture site, compartment syndrome (CS), and wound problems.

We reviewed 5-years period of our operative experience with paediatric forearm fractures. The purpose of this study was to review the results and compare the outcomes of IM fixation by Rush nails with titanium elastic nails (TENs), to better understand the risks and complications associated with these procedures.

\section{MATERIAL AND METHODS:}

This retrospective study was conducted in the Department of Orthopaedics,Lumbini Medical College and Teaching Hospital, Palpa after approval from the Institutional review board. We performed a retrospective review of all paediatric patients treated for diaphyseal forearm fractures between
January 2011 to December 2015. We collected data entered in computer, reviewed the clinical notes, operative summaries, and radiographic films for this selected group of patients to get the following information: age and gender of patients, date of injury, date of surgery, fracture location, injured limb, indications for surgery, type of implant used, duration of follow-up, time to radiographic union, final range of forearm motion, and postoperative complications. Any patient with a pathologic fracture, radial head fracture, Monteggia or Galeazzi fractures, isolated single bone fracture and compound (open) fracture were not included in this study. Both bone fractures where single bone fixation was done were also excluded from study.

Fracture union beyond 3 months was defined as a "delayed union" and failure of fracture union beyond 6 months was defined as a "nonunion ${ }^{5}$ Clinical outcomes were graded from the records available at final follow $\mathrm{u}$ according to classification system proposed by Jeffrey E. Martus et al ${ }^{6}$. This classification system include range of motion (ROM) of forearm and post operative surgical complications classified according to the Clavien-Dindo complication classification system table 1 .

Normal forearm range of forearm rotation was considered to be 70 degrees of pronation and 85 degrees of supination. An outcome was judged excellent if the range of motion was full and no complications greater than grade 1 occurred. A good result was based upon mild loss of motion ( $<10$ degrees $)$ with complications up to grade 2 . A fair result was reported if loss of motion was more significant (10 to 30 degrees) and complications were grade 3 or less in severity. A poor result was given if there was a significant loss of motion $(>30$ degrees) and/ or there were complications of grade 4 or 5 in severity Table 2 .

Table 1.Modification of the Clavien-Dindo Classification of Surgical Complications

\begin{tabular}{|l|l|l|}
\hline $\begin{array}{l}\text { Complication } \\
\text { grade }\end{array}$ & Definition & Examples \\
\hline 1 & $\begin{array}{l}\text { Deviation from a routine } \\
\text { postoperative course } \\
\text { without the need for } \\
\text { intervention }\end{array}$ & $\begin{array}{l}\text { Asymptomatic delayed } \\
\text { union } \\
\text { Prominent implant }\end{array}$ \\
\hline 2 & $\begin{array}{l}\text { Resolution after outpatient } \\
\text { management, } \\
\text { pharmacologic therapy, } \\
\text { or close observation }\end{array}$ & $\begin{array}{l}\text { Superficial infection } \\
\text { Transient nerve palsy }\end{array}$ \\
\hline 3 & $\begin{array}{l}\text { Requiring inpatient } \\
\text { management or } \\
\text { reoperation }\end{array}$ & $\begin{array}{l}\text { Deep infection } \\
\text { Implant migration } \\
\text { requiring early } \\
\text { removal }\end{array}$ \\
\hline 4 & $\begin{array}{l}\text { Complication that is limb } \\
\text { threatening, life } \\
\text { threatening, or resulting } \\
\text { in a permanent deficit }\end{array}$ & $\begin{array}{l}\text { Compartment } \\
\text { syndrome } \\
\text { Permanent nerve palsy } \\
\text { Radioulnar synostosis } \\
\text { Tendon rupture }\end{array}$ \\
\hline 5 & $\begin{array}{l}\text { Death of patient } \\
\text { Postoperative mortality } \\
\text { secondary to } \\
\text { anesthetic reaction }\end{array}$ \\
\hline
\end{tabular}


Table 2.Outcome Grading System

\begin{tabular}{|l|l|l|}
\hline Outcome Grade & Range of Motion & Complication Grade \\
\hline Excellent & Full & Grade 1 or none \\
\hline Good & $\begin{array}{l}\text { Loss of }<10 \text { degrees pronation } \\
\text { and/or supination }\end{array}$ & Grade 2 or less \\
\hline Fair & $\begin{array}{l}\text { Loss of } 10 \quad-30 \text { degrees } \\
\text { pronation and/or supination }\end{array}$ & Garde 3 or less \\
\hline Poor & $\begin{array}{l}\text { Loss of }>30 \text { degrees pronation } \\
\text { and/or supination }\end{array}$ & Up to grade 5 \\
\hline
\end{tabular}

Student $t$ test was used to compare the mean time to fracture union between Rush nailing and TENs nailing group. Using chi square $\left(\mathrm{x}^{2}\right)$ analysis we compared the outcomes between Rush nailing and TENs nailing group. A p-value of $<0.05$ was considered statistically significant.

\section{RESULTS:}

Forty five patients (mean age, 10.31 years; range, 515 years), 27 males and 18 females, met the inclusion criteria. Twenty seven $(60 \%)$ of them fractured due to fall while playing. Twenty five patients, 15 males and 10 females, were treated with IM nailing by Rush nails. Twenty patients, 12 males and 8 females, were treated with IM nailing by TENs $(\mathrm{P}=1)$. The mean age at the time of injury was 10.4 yrs (6 to 14) in Rush nail group and 10.2 yrs $(5$ to 15$)$ in TENs group $(\mathrm{P}=0.770)$.

Indication for surgery was unacceptable reduction following close reduction and cast application in $25(56.6 \%)$, loss of reduction in $2(4.4 \%)$, refracture in $3(6.7 \%)$, floating elbow in $1(2.2 \%)$ patients and in $14(31.1 \%)$ patients surgery was selected as a primary method of treatment. Side involved, location of fracture and type of reduction is shown in table 3 .

Table 3.Fracture pattern and type of reduction

\begin{tabular}{|l|l|l|l|l|}
\hline \multicolumn{2}{|c|}{} & TENs Group & $\begin{array}{l}\text { Rush nails } \\
\text { Group }\end{array}$ & Total \\
\hline \multirow{2}{*}{$\begin{array}{l}\text { Forearm } \\
\text { Fractured }\end{array}$} & Right & 14 & 15 & 29 \\
\cline { 2 - 6 } & Left & 6 & 10 & 16 \\
\hline $\begin{array}{l}\text { Fracture } \\
\text { location }\end{array}$ & $\begin{array}{l}\text { Proximal } \\
\text { third }\end{array}$ & 2 & 4 & 6 \\
\cline { 2 - 6 } & Middle third & 14 & 16 & 30 \\
\cline { 2 - 6 } & Distal third & 4 & 5 & 9 \\
\hline $\begin{array}{l}\text { Mini Open } \\
\text { reduction } \\
\text { required }\end{array}$ & Radius & $2(8 \%)$ & $1(5 \%)$ & 3 \\
\cline { 2 - 6 } & Ulna & $4(16 \%)$ & $3(15 \%)$ & 7 \\
\cline { 2 - 5 } & $\begin{array}{l}\text { Radius and } \\
\text { ulna both }\end{array}$ & $3(12 \%)$ & $1(5 \%)$ & 4 \\
\hline
\end{tabular}

The average time interval from injury to surgery was 2.4 days (range, 2 to 6 days) in Rush nailing group and 2.75 days (range, 2 to 5 days) in the TENs nailing $\operatorname{group}(\mathrm{P}=0.22)$

Reduction of fracture was achieved in $31(68.9 \%)$ patients by closed method and in $14(31.1 \%)$ patients minimal opening was made to reduce the fracture. In Rush nailing group 9 $(36 \%)$ patients (radius in $2(8 \%)$, ulna in $4(16 \%)$ and radius and ulna both in $3(12 \%)$ patients) required open reduction and in TENs group $5(25 \%)$ patients (radius in $1(5 \%)$, ulna in $3(15 \%)$ and both bone in $1(5 \%)$ patients) required open reduction $(\mathrm{p}=0.428)$

Patients in both groups were immobilized postoperatively in long arm cast or in above elbow posterior slab with an average duration of 4.88 weeks ( 4 to 8 wks ) in Rush nailing group and 4.8 weeks ( 4 to 8 wks $)$ in the TENs nailing group $(\mathrm{P}=0.842)$

There was no statistically significant difference for mean time to fracture union between the Rush nailing (10.56 weeks; range, 6 to 16 wks weeks) group and TENs nailing group (9.85weeks; range, 8 to 20 weeks $)(P=0.43)$. Out of 45 patients $36(80 \%)$ patients had normal forearm rotation and normal flexion and extension of elbow and wrist. Total of 9 $(20 \%)$ patients had restricted forearm rotation.

Postoperative complications occurred in $10(40 \%)$ patients in the Rush nailing group and in $6(30 \%)$ patients in the TENs group table 4 . Out of 10 complications 6 were asymptomatic delayed union that united without intervention within the 16 wks .Remaining 4 complications were grade 2 . One patient developed superficial radial nerve palsies, which resolved spontaneously without treatment. One superficial wound infection .Two patients developed a pin site irritation one on radial and one on ulnar site that resolved after implant removal .Loss of forearm rotation less than 30 degree was noted in 5 patients.

In TENs group there was one case of asymptomatic delayed union that united at 20 wks. Four patients had grade 2 complication one superficial wound infection, 3 symptomatic prominent implants and one had grade 3 complications in form of exposed implant at insertion site that required early removal at $16 \mathrm{wks}$ follow up. 4 patients had restriction forearm rotation less than 30 degree.

As per classification system proposed by Jeffrey E. Martus et al ${ }^{6}$ overall results were excellent in $27(60 \%)$ patients, good in $13(28.8 \%)$ patients, fair in 5(11.11\%) patients and there were no poor result. In Rush nailing group outcomes were excellent in $16(64 \%)$, good in $7(28 \%)$, fair in $2(8 \%)$ patients and no poor outcome were noted .In TENs nailing group outcomes were excellent in $11(55 \%)$, good in $6(30 \%)$, fair in $3(15 \%)$ patients no poor outcomes were noted. There was no statistically significant difference in outcomes between Rush nailing and TENs nailing group $. \mathrm{p}=0.65$ 
Table 4 complications and outcomes.

\begin{tabular}{|c|c|c|}
\hline & $\begin{array}{l}\text { Rush } \\
\text { nailing(25) }\end{array}$ & TENs (20) \\
\hline $\begin{array}{l}\text { Grade } 1 \text { complications } \\
\text { Asymptomatic delayed } \\
\text { union }\end{array}$ & 6 & 1 \\
\hline Grade 2 complications & & \\
\hline Superficial infection & 1 & 1 \\
\hline $\begin{array}{l}\text { Postoperative } \\
\text { neuropraxia ( transient) }\end{array}$ & 1 & 0 \\
\hline $\begin{array}{l}\text { Symptomatic Prominent } \\
\text { implant }\end{array}$ & 2 & 3 \\
\hline Grade 3 complications & 0 & 1 \\
\hline Grade 4 complications & 0 & 0 \\
\hline Grade 5 complication & 0 & 0 \\
\hline Overall complications & 10 & 6 \\
\hline $\begin{array}{c}\text { ROM } \\
\text { 1. Full }\end{array}$ & & \\
\hline $\begin{array}{ll}\text { 2. } & \text { Loss of }<10 \\
& \text { degrees } \\
\text { pronation and/or } \\
\text { supination }\end{array}$ & 3 & 2 \\
\hline $\begin{array}{l}\text { 3. Loss of } 10-30 \\
\text { degrees } \\
\text { pronation and/or } \\
\text { supination }\end{array}$ & 2 & 2 \\
\hline 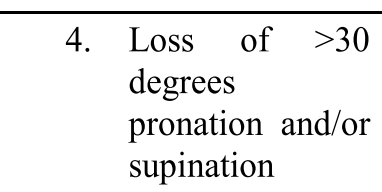 & 0 & 0 \\
\hline Outcomes & & \\
\hline
\end{tabular}

Latest follow up available was 28.72 wks (16 to $54 \mathrm{wks}$ ) in Rush nailing group and $25.2 \mathrm{wks}$ ( 16 to $54 \mathrm{wks}$ ) in Tens nailing group. $\mathrm{p}=.20$ Only $22(48.88 \%)$ patients followed for implant removal. Implant s were removed from 12 patients treated by Rush nails and from 10 patients treated by TENs nails. Cause of implant removal was solid union in all cases with complete obliteration of fracture line .Mean time at which implant was removed was 30.66(16 to 52) wks in Rush nailing grouping and 26.2 (16 to 52) wks in TENs nailing group $(\mathrm{p}=0.36)$ from the time of index surgery.

\section{DISCUSSION:}

Diaphyseal forearm fractures are common injuries among children. Closed reduction and cast immobilization remain the standard method of treatment for most of these fractures. ${ }^{1}$ Malreduction can leads to restriction in forearm rotation and function. There is variable opinion regarding acceptable degree of angulation and acceptable range of forearm rotation. A study by Daruwalla ${ }^{8}$ followed the longterm clinical outcomes of 53 forearm fractures treated with closed reduction and cast immobilization. He found that although 28 patients demonstrated notable limitations of supination, pronation, or both upon clinical examination, none of these patients complained of difficulties related to forearm motion. Morrey et al ${ }^{9}$ determined that the majority of daily activities can be performed with 100 degree of forearm rotation equally divided between pronation and supination. These two studies suggest that the residual angulation after nonoperative treatment may be well tolerated by children.

Several other investigators found that fracture angulation between 5 and 10 degrees at the midshaft of the forearm can lead to pronation deficits of $10 \%$ to $83 \%$ of normal and supination deficits of $5 \%$ to $27 \%$ of normal. ${ }^{10}$ Remodeling capacity of bone decreases with increasing age .Study has shown children 10 years or older do not predictably remodel to a significant degree. ${ }^{11,}$ Incidence of poor results of closed treatment of fractures in children older than 10 years old remains widely underreported. ${ }^{12}$ Considering this functional limitation due to malreduction of fracture and unpredictable remodeling capacity in older children there is increase in trend towards operative treatment of pediatric forearm fractures. There are situations, however, in which operative management is beneficial to avoid repeated reductions, additional corrective surgical procedures, and functional limitations. Plating is considered as standard method of surgical treatment in adults whereas IM nailing by Rush Nails, TENs or $\mathrm{K}$ wires is considered as standard method of fixation of forearm fractures in children.

Various studies have shown that IM nailing can provide precise fracture reduction, maintains stabilization for fracture healing, results in minimal cosmetic deformity, and facilitates easy removal of implants after treatment. ${ }^{3,4}$ However; IM nailing is not free of complications. Documented complications of this technique include nail site infections, skin irritation at nail insertion sites, fracture displacement after implant removal, implant migration or failure (bent or broken nails), loss of reduction, refracture, nerve and tendon injury, decreased range of motion, delayed union/nonunion, and compartment syndrome(CS).,4

In our study mean age of patients was 10.31 years similar to previous other studies and this is the age around which fixation is required to obtain better radiological and functional out come due to decreasing remodeling capacity. Reduction of fracture was achieved by closed method in $31(68.9 \%)$ patients and minimal opening was done to reduce the fracture in 14 
$(31.1 \%)$. The frequency of open reduction during IM fixation in previously closed fractures has been reported to be as high as $38 \%$ to $74.4 \%$ in the literature. ${ }^{13-16 .}$ We have not compared the outcome of closed with open nailing in our study. Merter Yalcinkaya et al ${ }^{15}$ concluded closed reduction or open reduction with a mini incision for intramedullary nailing yield similar functional results, with a similar complications rate in the treatment of pediatric unstable diaphyseal forearm fractures.

In this study post operative complications were evaluated with the modified Clavien-Dindo classification. This classification sysytem provides uniformity in the reporting of complications with objective criteria for the severity scale .An advantage of this classification is the elimination of the potential subjective bias associated with the grouping of complications as minor/major or mild/moderate/severe.

Outcomes and complications in the present study are comparable to other various studies ${ }^{3,4,13-17}$. table no 5 .Yalcinkaya $\mathrm{M}$ et $\mathrm{al}^{15}$ reporetd complications rate range from $4-38 \%$ in patients treated with intramedullary nailing and results were excellent in $82.2 \%$ and good in $17.8 \%$ of patients. Flynn JM et al ${ }^{3}$ reported $77.7 \%$ excellent, $14.6 \%$ fair and $7.8 \%$ poor results and showed that the overall complication rate in patients undergoing intramedullary nailing was $14.6 \%{ }^{3}$ The most common complication occurring in their series were infection, skin irritation by hard ware, pin back out ,delayed union and compartment syndrome.

In our series, minor complications were noted in $15(33.3 \%)$ cases and one $1(2.2 \%)$ major complication in form of exposed implant at insertion site which required early implant removal. No nonunion or malunion occurred in our series. There were no deep infections noted. Flynn noted compartment syndrome in those patients those were operated within first 24 hours but in our study no case was operated in first 24 hours that may be the reason of not getting any complication in the form of CS in our study. Parajuli NP et al reported excellent outcomes in $94 \%$ and good in $6 \%$ of patients. There were $8(16 \%)$ minor complication only. ${ }^{14}$

\section{CONCLUSION AND LIMITATIONS:}

Intramedullary Rush nail and TENs fixation for pediatric forearm fractures are minimally invasive procedure results are excellent to fair with acceptable poor results. Overall out comes in this study is excellent to fair with no poor result and reasonable complication rate .In current study there was no significant difference between Rush nailing and TENs nailing group regarding time for union and outcomes. Since Rush nails are easily available and affordable in developing countries like ours we can prefer Rush nails for intramedullary fixation of paediatric forearm fracture when indicated. Retrospective and non comparative nature of study was limitations of this study.
Table 5. Comparison of literature for similar studies.

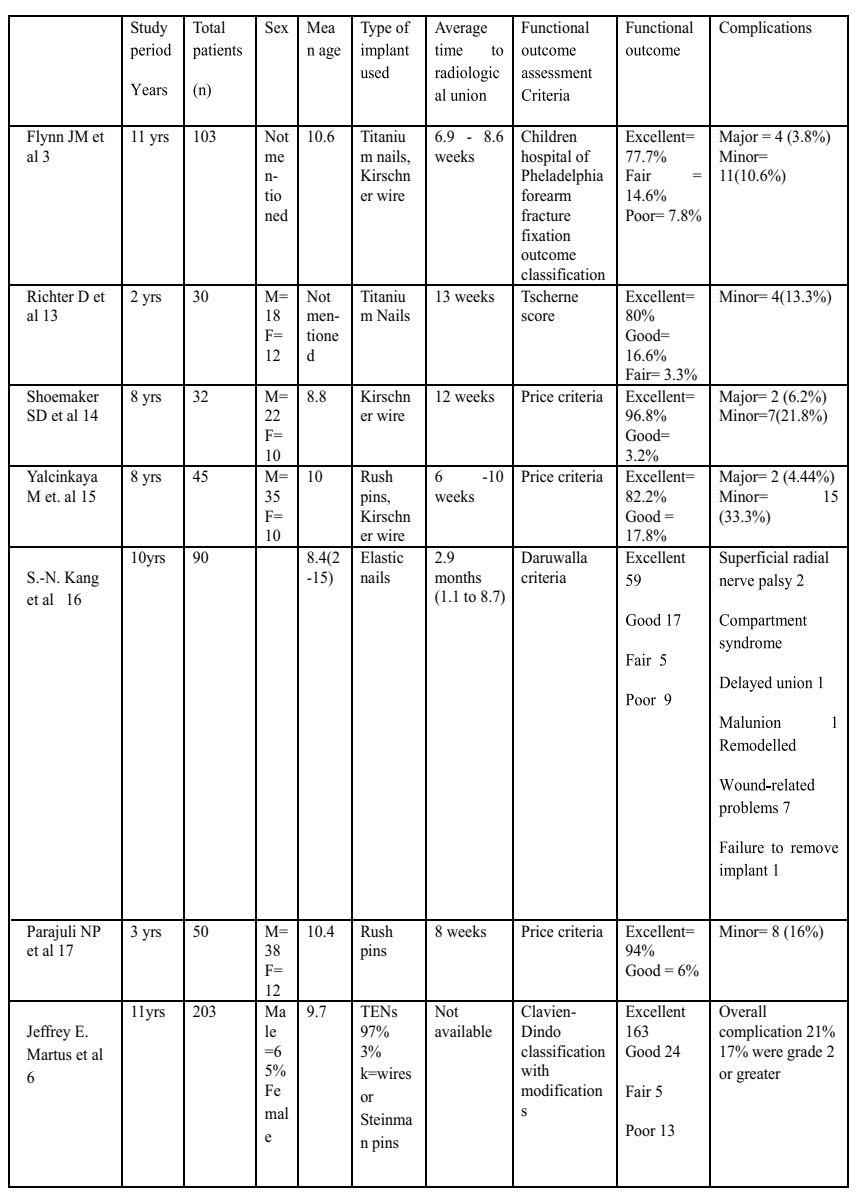

\section{REFERENCES:}

1. Rodríguez-Merchán EC. Pediatric fractures of the forearm. Clin Orthop 2005;432:65-72.

2. Schmittenbecher PP. State-of-the-art treatment of forearm shaft fractures. Injury. 2005;36:S-A25S-A34.

3. Flynn J, Jones K, Garner M, Goebel J. Eleven years experience in the operative management of pediatric forearm fractures. $J$ Pediatr Orthop 2010;30:3139

4. Akash Patel, Lily Li, Amarjit Anand. Systematic review: Functional outcomes and complications of intramedullary nailing versus plate fixation for both-bone diaphyseal forearm fractures in children. Injury, Int. J. Care Injured 45 (2014) 11351143

5. Schmittenbecher PP, Peter P, Fitze G, et al. Delayed healing of forearm shaft fractures in children after intramedullary nailing. J Pediatr Orthop.2008;28:303306. 
6. Jeffrey E. Martus, Ryan K. Preston, Jonathan G. Schoenecker et al Complications and Outcomes of Diaphyseal Forearm Fracture Intramedullary Nailing: A Comparison of Pediatric and Adolescent Age Groups J Pediatr Orthop Volume 33, Number 6, September 2013;33:598607

7. Clavien P, Barkun J, de Oliveira ML, et al. The Clavien-Dindo Classification of surgical complications.Ann Surg. 2009; 250:187196

8. Daruwalla JS. A study of radioulnar movements following fractures of the forearm in children. Clin Orthop. 1979;139. 114120.

9. Morrey B, Askew L, An K, et al. A biomechanical study of normal functional elbow motion. J Bone Joint Surg [Am]. 1981; 63:872877

10. Dumont $C E^{l}$, Thalmann $R$, Macy JC The effect of rotational malunion of the radius and the ulna on supination and pronation. JBone Joint Surg Br. 2002 Sep; 84(7): 1070-4.

11. Vittas D, Larsen E, Torp-Pedersen S. Angular remodeling of midshaft forearm fractures in children. Clin Orthop. 1991: 261264.

12. Kay S, Smith C, Oppenheim WL. Both-bone midshaft forearm fractures in children. JPediatr Orthop. 1986;6:306310

13. Richter D, Ostermann P, Ekkernkamp A, Muhr G, Hahn MP. Elastic intramedullary nailing: a minimally invasive concept in the treatment of unstable forearm fractures in children.J Pediatr Orthop 1998; 18:457-61
14. Shoemaker S. Comstock C. Mubarak S, Wenger DR, Chambers HG. Intramedullary Kirschner wire fixation of open or unstable forearm fractures in children. J Pediatr Orthop 1999; 19:329-37

15. Yalcinkaya M, Dogan A, Ozkaya V, Sokucu S, Uzumcugil O, Kabukcuoglu Y. Clinical results of intramedullary nailing following closed or mini open reduction in pediatric unstable diaphyseal forearm fractures. Acta Orthop Traumatol Turc2010; 44 (1): 7-13.

16. S.-N. Kang, J. Mangwani, M. Ramachandran, J. M. H. Paterson, M. Barry. Elastic intramedullary nailing of paediatric fractures of the forearm. A decade of experience in a teaching hospital in the united kingdom.J Bone Joint Surg [Br] 2011;93-B:262-5

17. Parajuli NP, Shrestha D, Dhoju D, Dhakal GR, Shrestha $R$, Sharma V. Intramedullary nailing for paediatric diaphyseal forearm bone fracture. Kathmandu Univ Med J. 2011;35 (3): 198-202 